\title{
GAMIFICATION OF AN UNDERGRADUATE PSYCHOLOGY STATISTICS LAB: BENEFITS TO PERCEIVED COMPETENCE
}

\author{
BELIZ HAZAN \\ CUNY Graduate Center \\ bhazan@gradcenter.cuny.edu \\ WEI ZHANG \\ New Jersey City University \\ wzhang1@njcu.edu \\ ECEM OLCUM \\ University of Central Florida \\ ecemolcum@knights.ucf.edu \\ ROSE BERGDOLL \\ CUNY Brooklyn College \\ rosebergdoll@gmail.com \\ EVAN GRANDOIT \\ CUNY Brooklyn College \\ evan.grandoit@gmail.com \\ FAIGY MANDELBAUM \\ CUNY Brooklyn College \\ faigy.mandelbaum@brooklyn.cuny.edu \\ GEORJEANNA WILSON-DOENGES \\ University of Wisconsin-Green Bay \\ wilsong@uwgb.edu \\ LAURA A. RABIN \\ CUNY Brooklyn College \\ lrabin@brooklyn.cuny.edu
}

\begin{abstract}
Teaching undergraduate psychology statistics poses challenges to instructors and students due to the perceived complexity of the material and lack of student motivation. With the goal of boosting student competency and engagement in statistics, our study introduced a gamified learning environment into the laboratory portion of the undergraduate psychology statistics course in which the gamified learning group was compared to the traditional group. Changes in intrinsic motivation, perceived competence, and objective pre-and post-test course content were assessed. Objective posttest scores were positively associated with perceived competence in statistics for the gamified learning group. Perceived competence is a strong predictor of achievement and foundational prerequisite of intrinsic motivation, suggesting that in contrast with the traditional group, students in the gamified group were further on the path towards developing intrinsic motivation and improved scholastic achievement.
\end{abstract}

Keywords: Statistics education research; Intrinsic motivation; Teaching strategies; Gamified learning; Game elements; Motivation

Statistics Education Research Journal, 17(2), 255-265, http://www.stat.auckland.ac.nz/serj

(c) International Association for Statistical Education (IASE/ISI), November, 2018 


\section{INTRODUCTION}

\subsection{STATEMENT OF PROBLEM AND STUDY HYPOTHESES}

Statistics instructors encounter many problems as they strive to engage students in what is considered a disliked and avoided social science course among undergraduate students (Gal \& Ginsburg, 1994; Prayoga \& Abraham, 2017; Slootmaeckers, Kerremans, \& Adriaensen, 2014; Smith, 2017; Verhoeven, 2006). Challenges associated with learning statistics include its level of difficulty, lack of interest in the topic, fear, boredom, and weak basic mathematics skills (Chiesi \& Primi, 2010; Dupuis et al., 2012; Gal, Ginsberg, \& Schau, 1997). Previous research has highlighted the effectiveness of gamification (Kapp, 2012; Nicholson, 2015), game-based learning (Huang, Johnson, \& Han, 2013; Kapp, 2012; Nadolny \& Halabi, 2016), project-based learning (Morgan, 1983), and flipped classrooms (Koo et al., 2016), for increasing student motivation, engagement, and performance in various academic domains. Preliminary data obtained from the use of the prototype 'Stats Cats,' a computer-based statistics game, suggests that gamification may be associated with student enjoyment in statistics (Walker \& Loch, 2014). Other innovative, active teaching methods have been utilized in statistics courses with reported benefits to learning - such as collaborative and cooperative learning, problembased learning and problem solving, case studies, course projects, simulations, and the use of technology (Tishkovskaya \& Lancaster, 2012).

The current study is one of the first to examine the benefits of a gamified learning environment for undergraduate psychology statistics students, and the first to specifically address intrinsic motivation through gamification in statistics laboratory courses. Based on a review of the gamification literature (see below), we hypothesized that for students undergoing a gamification intervention, objective posttest (statistics knowledge) scores would be associated with specific aspects of self-reported intrinsic motivation. We also hypothesized that students in a gamified laboratory group would score higher than students in a traditional laboratory group on objective, content-based multiple-choice questions that measure learning performance, and on subjective measures of (self-reported) intrinsic motivation at the end of the six-week study. Previous research has not identified an ideal time requirement for enhancing intrinsic motivation. Thus, for practical reasons related to the length of the course and increased difficulty of the material over the semester, we aimed to enhance this competency within the first six weeks of the 15 -week semester.

\subsection{LITERATURE REVIEW}

Gamification, the use of game design elements for non-game applications (Deterding, Dixon, Khaled, \& Nacke, 2011), has increased student engagement, motivation and performance in some educational settings (Cronk, 2012; Sailer, Hense, Mayr, \& Mandl, 2017; Stansbury \& Earnest, 2017). The foundation of these game elements includes the utilization of specific design principles (collaboration, competition, immediate feedback) and mechanics (points, badges, leaderboard), which are then tailored according to the required educational setting, course content, and application (online courses, courses without online support, e-learning) (Dicheva, Dichev, Agre, \& Angelova, 2015).

Self-Determination Theory (SDT) highlights the benefits of gamification by explaining how internal and external motivators impact self-motivation, performance, and well-being (Ryan \& Deci, 2000a; 2000b). Gamification incorporates numerous opportunities for self-motivation through both extrinsic and intrinsic reward-based game elements (Kapp, 2012; Sailer et al., 2017; Stansbury \& Earnest, 2017). Although extrinsic and intrinsic elements are associated with increased motivation, the patterns of intrinsic motivation as highlighted by the gamification process are stronger when a task is found to be inherently satisfying. Understandably, extrinsic motivation such as working towards completing a task to obtain external reward, may be easier to stimulate (Ryan \& Deci, 2000b). However, intrinsic motivation, which is more difficult to develop, and less vulnerable to extinction, is positively associated with longer lasting performance outcomes and increased academic achievement (Froiland \& Worrell, 2016).

Perceived competence, according to SDT, is one of the intrinsic motivation mechanisms that relates to a learner's confidence in his or her own ability or knowledge (Reilly, 2012; Ryan \& Deci, 2000a; $2000 \mathrm{~b}$ ). In the context of the current study, perceived competence is measured by students' evaluation 
of their performance in a statistics laboratory course. Perceived competence has been associated with increased intrinsic motivation (Deci \& Ryan, 1980; Vallerand \& Reid, 1984). Additionally, in educational research, higher perceived competence has been related to improved academic achievement (Yeung, Craven \& Kaur, 2014), and even a likability of statistics courses (Chiesi \& Primi, 2010).

Published research investigating the mechanisms by which gamification improves perceived competence and academic performance in statistics is minimal. Examples include statistics mobile applications that highlight the benefits of user-friendly and exciting out-of-class learning experiences (Cerego, 2016; Cerego Team, 2014; Walker \& Loch, 2014), and a 2017 study that demonstrates the positive impact of gamified learning on students' attitudes and performance in statistics classes (Smith, 2017). Overall, evidence suggests that in-class gamified learning environments positively impact student motivation, engagement, attitudes, and/or performance (Faghihi et al., 2014; Hong \& Masood, 2014; Smith, 2017). The combination of in-class gamified learning in a statistics course is a new and emerging area of study, and the reason why we introduced gamified learning into the laboratory portion of a psychology statistics course with the goals of developing student competency and engagement.

\section{METHOD}

\subsection{PARTICIPANTS AND PROCEDURE}

The study was conducted at an urban, public institution on the East Coast of the United States. Participants were college students, primarily between the ages of 18-24. All students who attended the first laboratory class of a psychology statistics course were invited to participate and all agreed. The psychology statistics course consisted of bi-weekly lectures (taught by an instructor for 75 minutes per lecture) and accompanying laboratory classes (led by graduate student lab instructors for 110 minutes per lab). In contrast with the formal environment of the lecture, the laboratory section was designed to be an interactive experience and was therefore an ideal environment for gamified learning. The lecture introduced students to the fundamentals of statistics such as descriptive statistics, correlation and regression, and hypothesis testing. The laboratory section built on the lecture material by reviewing course content and providing exercises using the Statistical Package for Social Sciences (SPSS). For the vast majority of students, this combined course represents the first exposure to statistical techniques and reasoning.

For the current study, the gamification intervention was administered in two of four laboratory classes during the first 6 weeks of the 15-week semester. Students had independently registered for one of four labs, of which two were taught in a traditional manner and two were adapted to incorporate gamified principles. The two graduate laboratory instructors who participated in this study were trained through online certificate programs such as Designing Gamified Learning Environments from the Online Learning Consortium (OLC), and Gamification, certified through Coursera. Each instructor administered one traditional and one gamified learning condition. Both the gamified and traditional groups completed the same objective and subjective outcome measures at weeks 1 and 6 . All participants were treated in accordance with American Psychological Association ethical guidelines (APA, 2002).

\subsection{LABORATORY EXPERIENCE}

The syllabi for the laboratory portion of the class were identical for the gamified and traditional laboratory groups. However, for the gamified group, resources such as class material and review questions were re-designed and included game elements typically used in educational settings. Elements included freedom to fail (unpenalized incorrect responses), rapid feedback (immediate provision of correct responses), progression (self-monitoring of statistics performance using customized mousepads), and storytelling (turning statistical computation assignments into narrative contexts) (Stott \& Neustaedter, 2013). Rapid feedback was provided through game mechanics (points, stamps, leaderboards), and behavior was reinforced through personalized avatars, points, and stamps, which were tracked on mousepads (converted into game boards) and leaderboards (provided on Dropbox). 
Gamified materials also included mini-boxes, a Jeopardy-like game, and mini projects. During mini-boxes, statistical computation assignments were presented on a PC through multiple-choice questions in a story-like form (storytelling). Students opened six different levels of "boxes" by answering sets of questions correctly. They were not penalized for incorrect responses (freedom to fail), and were given the correct answer upon submission (rapid feedback). During a modified version of the American television game show Jeopardy (Benek-Rivera \& Mathews, 2004), randomly assigned teams collaborated to rapidly respond to fill-in-the blank statistics questions provided by the instructor (collaboration, rapid feedback). Collaboration and competition opportunities were timed, correct responses per team were rewarded with points, and answers to incorrect responses were provided immediately (time constraints, group competition, rapid feedback). During timed mini project activities (time constraint), students worked in pairs (cooperation) on a statistical software package to solve data analysis practice questions in an independently chosen (freedom to choose) story-like format (story telling). Hints provided along the way acted as a scaffolding support, which is associated with gamification and performance outcomes (Faghihi et al., 2014).

Participants in the traditional laboratory group received statistics questions equivalent to the gamified group in terms of content but without the game elements (rapid feedback, freedom to choose, freedom to fail, scaffolding, storytelling, etc.). Mini-boxes were presented as a pen and paper multiplechoice test, and fill-in-the-blank statistics questions were offered instead of Jeopardy. Mini project tasks were also presented in pen and paper format, and once again, all game elements were removed. At the end of the 6 weeks, both groups received cupcakes for their participation and the three highest scoring students in the gamified group received USB flash drives.

\subsection{OBJECTIVE MEASURES}

All students received a pre- and posttest administered at weeks 1 and 6. Each test contained 15 multiple-choice questions that assessed knowledge of statistical material covered in the course. Questions were written by the course instructors and the pre- and posttests were identical in content with the exception of changes in numbers/values from pre- to posttest versions as demonstrated below:

Sample pretest question: Your scores on the first two exams of the semester are both 75 . What score would you need to obtain on exam 3 to have an overall grade of 83 (assuming all 3 exams contribute the same amount to the final grade)?

Sample posttest question: Your scores on the first three exams of the semester are 80, 85, and 69. What score would you need to obtain on exam 4 to have an overall average of 81 (assume all 4 exams contribute the same amount to the final grade)?

\subsection{SUBJECTIVE MEASURES}

Students completed the Intrinsic Motivation Inventory (IMI) at weeks 1 and 6 (Ryan, Koestner, \& Deci, 1991). The measure was modified slightly: 30 of the original 45 items were included and the word "activities" was replaced with "lab activities." The IMI utilized a 5-point Likert-type scale ranging from 1 (not at all true) to 5 (always true) with higher scores indicating more perceived competence, interest/enjoyment, or effort/importance. The Perceived Competence Subscale included 7 items that evaluated student understanding of class activities such as "After working at a lab activity for a while, I felt competent." One item was reverse coded. Cronbach's alpha was 0.898 at pretest and 0.899 at posttest showing strong reliability. The Interest/Enjoyment Subscale included 7 items that assessed student engagement such as "I enjoyed doing lab activities very much." Two items were reverse coded. Cronbach's alpha was 0.879 at pretest and 0.842 at posttest. The Effort/Importance Subscale included 5 items that evaluated how much effort students put into lab activities such as: "I put a lot of effort into this." Two items were reverse coded. Cronbach's alpha was 0.788 at pretest and 0.714 at posttest. The IMI also includes additional subscales (Pressure/Tension, Perceived Choice, Value/Usefulness, Relatedness) that were not used in the current study. 


\section{RESULTS}

The number of students for both groups totaled 99, of which 91 completed the objective pretest, 62 completed the subjective pretests, 84 completed the objective posttest, and 48 completed the subjective posttests. For the current study, we only analyzed data for students with both pre- and post-test scores on objective and subjective measures.

\subsection{THE RELATIONSHIPS BETWEEN OBJECTIVE AND SUBJECTIVE MEASURES}

We hypothesized that students in the gamified group would have greater associations between subscales of the IMI (Perceived Competence, Interest/Enjoyment, and Effort/Importance) and objective posttest scores when compared to the traditional learning group. To assess this hypothesis, we utilized Pearson correlation coefficients analyzed separately for each group. Descriptive statistics are shown in Table 1.

Table 1. Descriptive statistics for objective test scores and self-report variables

\begin{tabular}{lccccccc}
\hline & \multicolumn{3}{c}{ Gamified } & & \multicolumn{3}{c}{ Traditional } \\
\cline { 2 - 4 } \cline { 6 - 8 } & $n$ & $M$ & $S D$ & & $n$ & $M$ & $S D$ \\
\cline { 2 - 5 } 1 Pretest (\%) & 44 & 55.15 & 16.03 & & 47 & 43.4 & 16.67 \\
2 Posttest (\%) & 42 & 76.51 & 16.01 & & 42 & 71.9 & 15.55 \\
3 Interest Enjoyment (week 1) & 34 & 5.09 & 1.22 & & 28 & 4.35 & 1.03 \\
4 Perceived Competence (week 1) & 34 & 4.54 & 1.47 & & 28 & 4.27 & 1.14 \\
5 Effort Importance (week 1) & 34 & 5.16 & 1.21 & & 28 & 5.05 & 1.35 \\
6 Interest Enjoyment (week 6) & 32 & 5.08 & 1.06 & & 16 & 4.76 & 1.29 \\
7 Perceived Competence (week 6) & 32 & 4.93 & 1.24 & & 16 & 4.31 & 1.16 \\
8 Effort Importance (week 6) & 32 & 5.04 & 1.01 & & 16 & 4.4 & 1.24 \\
\hline
\end{tabular}

Note. $n=$ Sample size for the individual variable

In the gamified group, as shown in Tables $2 \mathrm{a}$ and $2 \mathrm{~b}$, objective pretest scores were statistically significantly associated with week 1 Interest/Enjoyment, $(r=0.45, p=0.007, n=34)$, Perceived Competence $(r=0.66, p<0.001, n=34)$, and week 6 Perceived Competence $(r=0.47, p=0.009 ; n=$ Interest/Enjoyment ( $r=0.50, p=0.006, n=29)$, Perceived Competence $(r=0.55, p=0.002, n=29)$, and week 6 Perceived Competence $(r=0.55, p=0.001, n=32$ ). In the traditional group (Tables $2 \mathrm{a}$ and $2 \mathrm{~b})$, the correlations were weak and no statistically significant associations were observed $(-0.242<r$ 's $<0.243$ ). All correlations were transformed using Fisher's $r$-to- $z$ transformation to allow a comparison of the difference of correlations. Results revealed a statistically significant difference between the gamified and traditional group for pretest and week 1 Interest/Enjoyment $(z=2.17, p=0.03)$, pretest and week 1 Perceived Competence $(z=2.83, p=0.005)$, and posttest and week 1 Perceived Competence $(z=2.98, p=0.003)$. There was no statistically significant difference between groups for pretest and week 1 Effort Importance $(z=1.11, p=0.267)$, pretest and week 6 Interest/Enjoyment $(z=1.08, p=$ $0.280)$, pretest and week 6 Perceived Competence $(z=1.88, p=0.06)$, posttest and week 1

Table 2a. Pearson correlations for objective pretest scores and self-report variables

\begin{tabular}{lccc}
\hline & $\begin{array}{c}\text { Gamified group } \\
r(p)\end{array}$ & $\begin{array}{c}\text { Traditional group } \\
r(p)\end{array}$ & $\begin{array}{c}\text { Test of difference of } \\
\text { correlations, } z(p)\end{array}$ \\
\hline & \multicolumn{2}{c}{ Pretest $(\%)$} \\
1 Pretest (\%) & 1 & 1 & \\
2 Interest Enjoyment (week 1) & $0.45(.007)$ & $-0.10(.627)$ & $2.17(.03)$ \\
3 Perceived Competence (week 1) & $0.66(.000)$ & $0.04(.858)$ & $2.83(.005)$ \\
4 Effort Importance (week 1) & $0.19(.275)$ & $-0.10(.599)$ & $1.11(.267)$ \\
5 Interest Enjoyment (week 6) & $0.11(.556)$ & $-0.24(.384)$ & $1.08(.280)$ \\
6 Perceived Competence (week 6) & $0.47(.009)$ & $-0.12(.678)$ & $1.88(.060)$ \\
7 Effort Importance (week 6) & $-0.27(.153)$ & $-0.24(.399)$ & $-0.11(.912)$ \\
\hline
\end{tabular}


Table 2b. Pearson correlations for objective posttest scores and self-report variables

\begin{tabular}{lccc}
\hline & $\begin{array}{c}\text { Gamified group } \\
r(p)\end{array}$ & $\begin{array}{c}\text { Traditional group } \\
r(p)\end{array}$ & $\begin{array}{c}\text { Test of difference of } \\
\text { correlations, } z(p)\end{array}$ \\
\hline & \multicolumn{2}{c}{ Posttest $(\%)$} & \\
1 Posttest (\%) & 1 & 1 & $1.44(.149)$ \\
2 Interest Enjoyment (week 1) & $0.50(.006)$ & $0.16(.471)$ & $2.98(.003)$ \\
3 Perceived Competence (week 1) & $0.55(.002)$ & $-0.18(.391)$ & $0.66(.509)$ \\
4 Effort Importance (week 1) & $0.08(.678)$ & $-0.10(.659)$ & $1.51(.131)$ \\
5 Interest Enjoyment (week 6) & $0.31(.087)$ & $-0.18(.495)$ & $1.14(.254)$ \\
6 Perceived Competence (week 6) & $0.56(.001)$ & $0.24(.365)$ & $-0.10(.920)$ \\
7 Effort Importance (week 6) & $-0.22(.223)$ & $-0.19(.484)$ & \\
\hline
\end{tabular}

Interest/Enjoyment $(z=1.44, p=0.149)$, posttest and week 1 Effort Importance $(z=0.66, p=0.509)$, posttest and week 6 Interest Enjoyment $(z=1.51, p=0.131)$, posttest and week 6 Perceived Competence $(z=1.14, p=0.254)$, or posttest and week 6 Effort Importance $(z=-0.10, p=0.920)$.

Due to the statistically significant correlations found only in the gamified group, we conducted a hierarchical multiple regression analysis for the gamified group to further determine the contribution of the subjective measures to the objective posttest scores. As seen in Table 3a, in the gamified group, week 6 Perceived Competence statistically significantly predicted objective posttest scores $(S E=2.60$, $\hat{\beta}=0.76, t=3.45, p=0.002 ; n=26$ ); where objective pretest scores and week 1 Perceived Competence were modeled as controlled variables (as statistically significant associations were found in correlation analysis). We further controlled for week 6 Interest/Enjoyment and Effort/Importance as additional controlled variables in the model. The predicting effects of week 6 Perceived Competence remained unchanged $(S E=3.07, \hat{\beta}=0.614, t=2.357, p=0.026, n=26)$. As seen in Table $3 b$, the same effects were not observed in the traditional group.

Table 3a. Selected factors (perceived competence in predicting gamified group posttest scores

\begin{tabular}{|c|c|c|c|c|c|c|c|}
\hline & \multicolumn{2}{|c|}{$\begin{array}{c}\text { Unstandardized } \\
\text { coefficient }\end{array}$} & \multirow{2}{*}{$\begin{array}{c}\begin{array}{c}\text { Standardized } \\
\text { coefficient }\end{array} \\
\hat{\beta} \\
\end{array}$} & \multirow[b]{2}{*}{$t$} & \multirow[b]{2}{*}{$p$} & \multirow[b]{2}{*}{$95 \%$ CI } & \multirow[b]{2}{*}{$\Delta R^{2}$} \\
\hline & $B$ & $S E$ & & & & & \\
\hline Step 1 & & & & & & & 0.162 \\
\hline Pretest & 0.17 & 0.22 & 0.17 & 0.76 & 0.454 & $(-0.29,0.62)$ & \\
\hline P. competence (wk 1) & 3.04 & 2.41 & 0.28 & 1.26 & 0.220 & $(-1.95,8.03)$ & \\
\hline Step 2 & & & & & & & 0.295 \\
\hline Pretest & 0.00 & 0.19 & 0.00 & 0.02 & 0.981 & $(-0.38,0.39)$ & \\
\hline P. competence (wk 1) & -1.53 & 2.39 & -0.14 & -0.64 & 0.528 & $(-6.48,3.42)$ & \\
\hline P. competence (wk 6) & 8.98 & 2.60 & 0.76 & 3.45 & 0.002 & $(3.59,14.38)$ & \\
\hline
\end{tabular}

Table 3b. Selected factors (perceived competence) in predicting control group posttest scores

\begin{tabular}{|c|c|c|c|c|c|c|c|}
\hline & \multicolumn{2}{|c|}{$\begin{array}{c}\text { Unstandardized } \\
\text { coefficient }\end{array}$} & \multirow{2}{*}{$\begin{array}{c}\text { Standardized } \\
\text { coefficient } \\
\hat{\beta} \\
\end{array}$} & \multirow[b]{2}{*}{$t$} & \multirow[b]{2}{*}{$p$} & \multirow[b]{2}{*}{$95 \% \mathrm{CI}$} & \multirow[b]{2}{*}{$\Delta R^{2}$} \\
\hline & $B$ & $S E$ & & & & & \\
\hline Step 1 & & & & & & & 0.125 \\
\hline Pretest & -0.30 & 0.30 & -0.35 & -0.99 & 0.355 & $(-1.02,0.42)$ & \\
\hline P. competence (wk 1) & -0.92 & 4.54 & -0.07 & -0.20 & 0.845 & $(-11.66,9.82)$ & \\
\hline Step 2 & & & & & & & 0.008 \\
\hline Pretest & -0.25 & 0.39 & -0.29 & -0.64 & 0.546 & $(-1.21,0.71)$ & \\
\hline P. competence (wk 1) & -1.97 & 6.70 & -0.15 & -0.29 & 0.779 & $(-18.37,14.42)$ & \\
\hline P. competence (wk 6) & 1.54 & 6.74 & 0.14 & 0.23 & 0.827 & $(-14.96,18.04)$ & \\
\hline
\end{tabular}




\subsection{EFFECTS OF INTERVENTION ON OBJECTIVE AND SUBJECTIVE POSTTEST SCORES}

We hypothesized that students in the gamified group would differ from the traditional group on the objective posttest scores. The percentage of correct responses was calculated out of 15 multiple-choice questions. Independent samples $t$-test showed that pretest scores for the traditional group $(M=43.40$, $S D=16.67)$ were statistically significantly lower than that for the gamified group $(M=55.15, S D=$ $16.03)$, mean difference $=-11.75 ; 95 \%$ CI $(-18.57,-4.93), t(89)=-3.42, p<0.001$. After controlling for the pretest scores, analysis of covariance (ANCOVA) revealed no statistically significant difference in posttest scores between the traditional $(M=72.00, S D=15.48)$, and gamified groups $(M=77.66, S D$ $=15.81), F(1,74)=0.33, p=0.565$.

There was no statistically significant difference between the groups in the week 1 Perceived Competence, $t(60)=-0.790, p=0.433$, and Effort Importance, $t(60)=-0.340, p=0.735$. However, there was a statistically significant difference between the groups in the week 1 Interest/Enjoyment, $t(60)=-2.55, p=0.013$. Furthermore, after controlling for the corresponding week 1 measures, ANCOVA showed that there were no statistically significantant group differences in week 6 for Perceived Competence (traditional: $M=4.42, S D=1.26$; gamified: $M=5.03, S D=1.22), F(1,33)=$ $1.18, p=0.285$, Effort/Importance (traditional: $M=4.68, S D=1.36$; gamified: $M=5.15, S D=0.99$ ), $F(1,33)=0.12, p=0.730$ ), and Interest/Enjoyment (traditional: $M=5.21, S D=1.22$; gamified: $M=$ $5.28, S D=1.02), F(1,33)=2.30, p=0.139$. The summary of the ANCOVA results are shown in Table 4.

Table 4. ANCOVA results for week 6 measures

\begin{tabular}{lccccc}
\hline Outcome & $\begin{array}{c}\text { Traditional } \\
M(S D)\end{array}$ & $\begin{array}{c}\text { Gamified } \\
M(S D)\end{array}$ & $\begin{array}{c}\text { Difference } \\
\text { of means }^{\mathrm{a}}\end{array}$ & 95\% CI & $p$ \\
\hline Posttest & $73.70(2.45)$ & $75.82(2.56)$ & -2.11 & $(-9.40,5.17)$ & 0.565 \\
P. competence (wk 6) & $4.59(.30)$ & $4.97(.18)$ & -0.38 & $(-1.10,0.334)$ & 0.285 \\
Effort/Interest (wk 6) & $4.93(.30)$ & $5.05(.18)$ & -0.12 & $(0-.83,0.59)$ & 0.730 \\
Interest/Enjoyment (wk 6) & $5.57(.23)$ & $5.15(.14)$ & 0.42 & $(-0.14,0.98)$ & 0.139 \\
\hline
\end{tabular}

${ }^{a}$ Traditional minus Gamified

\section{DISCUSSION}

In the current study, we found partial support for the hypothesis that the objective post-test scores of psychology statistics students in a gamified learning group would be associated with aspects of intrinsic motivation (perceived competence, interest/enjoyment, effort/importance) when compared to students in a traditional learning group. After controlling for the objective pretest and week 1 perceived competence, a significant positive association was observed between week 6 perceived competence and week 6 posttest scores in the gamified but not in the traditional group. Both correlation and regression results supported that the size of the effect for week 6 perceived competence to predict week 6 posttest scores was medium to large (Acock, 2014; Cohen, 1988). This may explain why for students in the gamified group, those who rated themselves as more competent (e.g., "I think I did pretty well..."; "I am satisfied with my performance...") were more likely to have higher test performance, whereas test performance of students in the traditional group was not predicted by their concurrent perceived competence levels.

Our findings may relate to the fact that game elements utilized in the gamified group helped students develop a better understanding of their own competence levels. For example, the use of feedback has been reported to play an essential role in increasing competence (Ryan \& Deci, 2000b; Vallerand \& Reid, 1984). Sailer and colleagues (2017) argued that game elements such as points, badges, and leaderboards can contribute to satisfying the need for competence, because they provide types of feedback that are direct indicators of the levels of performance. This suggests that the rapid feedback component (immediately providing correct answers) of the gamified group may be a contributing factor in the association between increased perceived competence and objective scores as opposed to other game elements. 
Ultimately, students in the gamified group may have had more opportunities to self-evaluatewhich could lead to enhanced self-reflection accuracy, better planning, study strategies (Zimmerman, Moylan, Hudesman, White, \& Flugman, 2011), and perceived competence. Although perceived competence is linked with the development of motivation (Deci \& Ryan, 1980; Ryan \& Deci, 2000a; $2000 \mathrm{~b}$ ), studies highlighting the effectiveness of game elements on student motivation in educational settings demonstrate mixed findings (Hamari, Koivisto, \& Sarsa, 2014; Hanus \& Fox, 2015; Stansbury $\&$ Earnest, 2017). Admittedly, there are numerous game elements and components used while assessing change in students' attitudes and performance. Future studies should therefore focus on the effects of individual game elements on each component of intrinsic motivation and learning performance to isolate the most valuable components (Sailer et al., 2017).

Our hypothesis that students in the gamified group would score higher on objective and subjective test measures as compared to the traditional learning group was not supported. There was no evidence of a difference between groups regarding students' knowledge of course content and self-reported intrinsic motivation as measured by perceived competence (as well as interest/enjoyment, and effort/importance). This is consistent with previous studies documenting controversial results utilizing educational gamification design principles and game mechanics (Hanus \& Fox, 2015; Sailer et al., 2017; Stansbury \& Earnest, 2017). A possible reason for this null finding can be explained by our use of the SDT, which proposes that once psychological needs such as competence are fulfilled, intrinsic motivation is increased (Ryan \& Deci, 2000a, 2000b). Although students in the gamified group did not show an increase in perceived competence, they demonstrated an association between higher perceived competence and greater performance. Because awareness of one's abilities is related to perceived competence, students in the gamified group who were more aware of their performance, may be one step closer to developing increased perceived competence, leading to intrinsic motivation, and enhanced academic performance.

Limitations of this study, which lead us to conceptualize the data as preliminary, include 1) lack of randomization due to the preassigned roster through the college's psychology department; 2) baseline differences between the two groups in test performance at week 1 (which we statistically controlled for); and 3) small sample size of the traditional group jeopardizing the power of the study. Additionally, our game design included numerous mechanisms such as points and leaderboards, as well as gamification design principles such as collaboration, competition, and rapid feedback. Although these components may have influenced perceived competence (which was found only in the gamification group), we neither measured nor identified specific gamification components and their relationship to perceived competence.

Based on current findings, the implementation of gamification in statistics education may contribute to the prediction of academic achievement based on perceived competence. This can be of value to instructors looking to incorporate game elements into their classrooms to boost learning and performance. Research has demonstrated that gamified education utilizing badges and points can improve motivation and course performance of students in non-statistics classrooms (Chung-Ho, 2016). Additionally, gamified learning incorporates elements that may foster intrinsic motivation through both intrinsic and extrinsic behaviors and rewards. However, we would probably need to execute our study for longer than 6 weeks to achieve benefits to all three aspects of intrinsic motivation that were examined in this study.

To our knowledge, this is the first study that utilized gamification in an undergraduate psychology statistics laboratory course and compared it to a traditional learning environment, assessing for both subjective (intrinsic motivation) and objective outcomes (test performance scores). This study provides preliminary evidence for the contribution of a gamified learning environment to students' perceived competence in an undergraduate statistics course. Future studies may apply and evaluate each game component separately. User experience research studies might be conducted to obtain feedback about the current design and create a better user-centered gamified learning environment.

New educational technology such as the exciting mobile statistics application Statistics Personalized Learning (StatsPL), which is funded by the Bill and Melinda Gates Foundation, aims to boost student statistical abilities through making statistics user-friendly, palatable, and adaptable (Cerego, 2016; Cerego Team, 2014). If combined with in-class statistics gamification, the results of personalized and gamified learning may be the key to tipping the scale of motivation and performance. With perceived competence possibly impacting students' course experience and learning in a mere 6 
weeks, we feel there is potential for gamified statistics classes to alter how students view and perform in this disliked but critical social science course.

\section{ACKNOWLEDGEMENTS}

This project was supported, in part, by a CUNY Provost's Digital Innovation Grant. The authors wish to thank the undergraduate student participants as well as Dr. David Owen for his consultation regarding the statistical analysis.

\section{REFERENCES}

Acock, A. C. (2014). A Gentle Introduction to Stata (4th ed.). College Station, TX: Stata Press.

American Psychological Association. (2002). Ethical principles of psychologists and code of conduct. American Psychologist, 57(12), 1060-1073.

Benek-Rivera, J., \& Mathews, V. E. (2004). Active learning with Jeopardy: Students ask the questions. Journal of Management Education, 28(1), 104-118.

Cerego. (2016, July 6). Cerego courseware: Statistics for the $21^{\text {st }}$ century student [Video File].

[Online: https://www.youtube.com/watch?v=yZB4DC-4HzE ]

Cerego Team (2014, September 30). Introducing Statspl: A revolutionary new course we're developing with the Bill \& Melinda Gates Foundation [Web blog post].

[Online: www.cerego.com/blog/2014/09/30/introducing-statspl-a-revolutionary-new-course ]

Chiesi, F., \& Primi, C. (2010). Cognitive and non-cognitive factors related to students' statistics achievement. Statistics Education Research Journal, 9(1), 6-26.

[Online: https://www.stat.auckland.ac.nz/ iase/serj/SERJ9(1)_Chiesi_Primi.pdf ]

Chung-Ho, S. (2016). The effects of students' motivation, cognitive load and learning anxiety in gamification software engineering education: A structural equation modeling study. Multimedia Tools and Applications, 75(16), 10013-10036.

Cohen, J. (1988). Statistical Power Analysis for the Behavioral Sciences. Hillside, NJ: Lawrence Erlbaum Associates.

Cronk, M. (2012, June). Using gamification to increase student engagement and participation in class discussion. Paper presented at the World Conference on Educational Multimedia, Hypermedia, and Telecommunications, Chesapeake, VA.

Deci, E. L., \& Ryan, R. M. (1980). The empirical exploration of intrinsic motivational processes. In L. Berkowitz (Ed.), Advances in Experimental Social Psychology, 13, 39-80. New York: Academic.

Deterding, S., Dixon, D., Khaled, R., \& Nacke, L. (2011). From game design elements to gamefulness: Defining gamification. In A. Lugmayr et al. (Eds.), MindTrek conference: Envisioning future media environments (pp. 9-15). Tampere, Finland: ACM.

Dicheva, D., Dichev, C., Agre, G., \& Angelova, G. (2015). Gamification in education: A systematic mapping study. Educational Technology \& Society, 18(3), 1-14.

Dupuis, D. N., Medhanie, A., Harwell, M., Lebau, B., Monson, D., \& Post, T. R. (2012). A multiinstitutional study of the relationship between high school mathematics achievement and performance in introductory college statistics. Statistics Education Research Journal, 11(1), 4-20. [Online: https://iase-web.org/documents/SERJ/SERJ11(1)_Dupuis.pdf ]

Faghihi, U., Brautigam, A., Jorgenson, K., Martin, D., Brown, A., Measures, E., \& MaldonadoCouchard, S. (2014). How gamification applies for educational purpose specially with college algebra. Procedia Computer Science, 41, 182-187.

Froiland, J. M., \& Worrell, F. C. (2016). Intrinsic motivation, learning goals, engagement, and achievement in a diverse high school. Psychology in the Schools, 53(3), 321-336.

Gal, I., \& Ginsburg, L. (1994). The role of beliefs and attitudes in learning statistics: Towards an assessment framework. Journal of Statistics Education, 2(2), 1-15.

[Online: https://doi.org/10.1080/10691898.1994.11910471]

Gal, I., Ginsburg, L., \& Schau, C. (1997). Monitoring attitudes and beliefs in statistics education. In I. Gal \& J. B. Garfield (Eds.), The assessment challenge in statistics education (pp. 37-51). Amsterdam, The Netherlands: IOS Press. 
Hamari, J., Koivisto, J., \& Sarsa, H. (2014). Does gamification work?-A literature review of empirical studies on gamification. In R. Sprague et al. (Eds.), 47th Hawaii International Conference on System Sciences (pp. 3025-3034). Waikoloa, HI.

Hanus, M. D., \& Fox, J. (2015). Assessing the effects of gamification in the classroom: A longitudinal study on intrinsic motivation, social comparison, satisfaction, effort, and academic performance. Computers \& Education, 80, 152-161.

Hong, G. Y., \& Masood, M. (2014). Effects of gamification on lower secondary school students' motivation and engagement. International Scholarly and Scientific Research \& Innovation, 8(12), 3750-3757.

Huang, W. D., Johnson, T. E., \& Han, S. H. C. (2013). Impact of online instructional game features on college students' perceived motivational support and cognitive investment: A structural equation modeling study. The Internet and Higher Education, 17, 58-68.

Kapp, K. M. (2012). The gamification of learning and instruction: Game-based methods and strategies for training and education. Hoboken, NJ: John Wiley \& Sons.

Koo, C. L., Demps, E. L., Farris, C., Bowman, J. D., Panahi, L., \& Boyle, P. (2016). Impact of flipped classroom design on student performance and perceptions in a pharmacotherapy course. American Journal of Pharmaceutical Education, 80(2), 33.

Morgan, A. (1983). Theoretical aspects of project-based learning in higher education. British Journal of Educational Technology, 14(1), 66-78.

Nadolny, L., \& Halabi, A. (2016). Student participation and achievement in a large lecture course with game-based learning. Simulation and Gaming, 47(1), 51-72.

Nicholson, S. (2015). A RECIPE for meaningful gamification. In L. Wood \& T. Reiners (Eds.), Gamification in education and business (pp. 1-20). New York: Springer.

Prayoga, T., \& Abraham, J. (2017). A psychological model explaining why we love or hate statistics. Kasetsart Journal of Social Sciences, 38(1), 1-8.

Reilly, M., J. (2012). An investigation of the relationship among social support, motivation, perceived competence, and pursuit of a baccalaureate degree among associate degree nurse graduates (Unpublished doctoral dissertation). Graduate Center City University of New York. Retrieved from ProQuest Dissertations and Theses database. (UMI:3499317)

Ryan, R. M., \& Deci, E. L. (2000a). Self-determination theory and the facilitation of intrinsic motivation, social development, and well-being. American Psychologist, 55(1), 68-78.

Ryan, R. M., \& Deci, E. L. (2000b). Intrinsic and extrinsic motivations: Classic definitions and new directions. Contemporary Educational Psychology, 25(1), 54-67.

Ryan, R. M., Koestner, R., \& Deci, E. L. (1991). Varied forms of persistence: When free-choice behavior is not intrinsically motivated. Motivation and Emotion, 15, 185-205.

Sailer, M., Hense, J. U., Mayr, S. K., \& Mandl, H. (2017). How gamification motivates: An experimental study of the effects of specific game design elements on psychological need satisfaction. Computers in Human Behavior, 69, 371-380.

Slootmaeckers, K., Kerremans, B., \& Adriaensen, J. (2014). Too afraid to learn: Attitudes towards statistics as a barrier to learning statistics and to acquiring quantitative skills. Politics, 34(2), 191200.

Smith, T. (2017). Gamified modules for an introductory statistics course and their impact on attitudes and learning. Simulation \& Gaming, 48(6), 832-854.

Stansbury, J. A., \& Earnest, D. R. (2017). Meaningful gamification in an industrial/organizational psychology course. Teaching of Psychology, 44(1), 38-45.

Stott, A., \& Neustaedter, C. (2013). Analysis of gamification in education (Report No. 2013-0422-01). Surrey, BC, Canada: Connections Lab, Simon Fraser University.

Tishkovskaya, S., \& Lancaster, G. (2012). Statistical education in the $21^{\text {st }}$ century: A review of challenges, teaching innovations and strategies for reform. Journal of Statistics Education, 20(2), $1-24$.

[Online: https://doi.org/10.1080/10691898.2012.11889641 ]

Vallerand, R. J., \& Reid, G. (1984). On the causal effects of perceived competence on intrinsic motivation: A test of cognitive evaluation theory. Journal of Sport Psychology, 6(1), 94-102.

Verhoeven, P. (2006). Statistics education in the Netherlands and Flanders: An outline of introductory courses at universities and colleges. In A. Rossman \& B. Chance (Eds.), Proceedings of the Seventh 
International Conference on Teaching of Statistics (ICOTS-7), Salvador, Brazil. Voorburg, The Netherlands: International Statistical Institute.

[Online: https://iase-web.org/documents/papers/icots7/3A4_VERH.pdf ]

Walker, L., \& Loch, B. (2014). Gamifying undergraduate statistics: A HERDSA seed grant project. HERDSA News, 36(1), 7.

Yeung, A. S., Craven, R. G., \& Kaur, G. (2014). Influencing of mastery goal and perceived competence on educational outcomes. Australian Journal of Educational and Developmental Psychology, 14, $117-130$.

Zimmerman, B. J., Moylan, A., Hudesman, J., White, N., \& Flugman, B. (2011). Enhancing selfreflection and mathematics achievement of at-risk urban technical college students. Psychological Test and Assessment Modeling, 53(1), 108-127.

BELIZ HAZAN

CUNY Graduate Center

365 5th Ave, New York, NY 10016

USA 